\title{
VALORES DE ENERGIA METABOLIZÁVEL DE ALIMENTOS PARA PINTOS DE CORTE NA FASE PRÉ-INICIAL
}

\author{
Metabolizable energy values of feedstuffs for young chickens from pre-initial phase
}

\author{
Kamilla Ribas Soares ${ }^{1}$, Antonio Gilberto Bertechini ${ }^{2}$, Édison José Fassani ${ }^{3}$, Paulo Borges Rodrigues ${ }^{2}$, \\ Elias Tadeu Fialho ${ }^{2}$, Adriano Geraldo ${ }^{4}$, Jerônimo Ávito Gonçalves de Brito ${ }^{5}$
}

\begin{abstract}
RESUMO
Um experimento foi realizado no Setor de Avicultura da Universidade Federal de Lavras (UFLA), com duração de 6 dias, para determinar os valores energéticos de fontes protéicas para pintos de corte na fase pré-inicial. Utilizaram-se 480 pintos machos, Cobb, com 1 dia de idade que foram submetidos à metodologia de coleta total de excretas e distribuídos em 9 tratamentos com 6 repetições. Os tratamentos foram compostos por 4 alimentos protéicos de origem vegetal (farelo de soja, soja integral tostada, soja micronizada e farelo de glúten de milho) que substituíram a ração referência (RR) em $30 \%$ e 4 alimentos protéicos de origem animal (farinha de carne e ossos $40 \%$ e $45 \%$ de PB, farinha de peixe e farinha de vísceras), que substituíram a RR em 20\%. Simultaneamente, 6 repetições de 8 aves foram colocadas em jejum para a determinação das perdas endógenas. As variáveis estudadas foram energia metabolizável aparente (EMA), verdadeira (EMV) e as EMA e EMV corrigidas para balanço de nitrogênio (EMAn, EMVn). Os alimentos de origem vegetal obtiveram valores de energia inferiores aos obtidos nas tabelas usuais de composição dos alimentos e os alimentos de origem animal, valores superiores.
\end{abstract}

Termos para indexação: energia, frango de corte, fase pré-inicial.

\section{ABSTRACT}

An experiment was conducted in the Poultry Farm Sector of the Universidade Federal de Lavras (UFLA) with 6 days period duration to determine the energy values in protein sources for broiler chickens in the pre-initial phase. A total of 480 male chickens from Cobb line with one day old were submitted to the method of total excreta collection, allotted to nine treatments with six replicates each. The experimental unit consisted of eight chickens. The treatments were: 1- reference diet (RD); 2- RD with the addition of soybean meal; 3- RD with the addition of toasted soybean meal; 4- RD with the addition of micronized soybean meal; 5- RD with corn gluten meal; 6- RD with meat and bone meal 40; 7 - RD meat and bone meal 45; 8 $\mathrm{RD}$ with fish meat; 9- RD with viscera meal. The protein feeds from vegetal by-products replaced RD by $30 \%$ and the protein feeds from animal by-product replaced by $20 \%$. Simultaneously, six replicates of 8 chickens were placed in fasting to determine endogenous losses. The analyzed variables were the values of apparent metabolizable energy (AME), true metabolizable energy (TME) and the nitrogen balance corrected AME and TME (AMEn and TMEn, respectively). The protein feeds from vegetal by-products shown ME decresead in relation to usually table of the feed composition table and the protein feeds from animal by-products shown higher values than those cited in the current literature or feed tables.

Index terms: energy, broiler chickens, pre-initial phase.

(Recebido para publicação em $1^{\circ}$ de abril de 2004 e aprovado em 20 de Janeiro de 2005)

\section{INTRODUÇÃO}

Na criação de frangos de corte, durante a fase pré-inicial há intenso desenvolvimento corporal e do sistema digestório. Assim, a demanda por nutrientes de alta qualidade é elevada. Apesar das aves nesta fase, possuírem reservas nutricionais advindas do saco vitelino, que asseguram a sobrevivência até o terceiro dia de vida, estas não são capazes de suprir suas exigências nutricionais, considerando que, eles ainda não possuem o trato gastrointestinal totalmente desenvolvido, princi- palmente em relação a sua baixa concentração enzimática. Dessa forma, uma nutrição adequada desde os primeiros dias é importante para melhorar o aproveitamento dos nutrientes e, conseqüentemente, seu desempenho.

Por muitos anos, produtores de frango de corte têm usado programas nutricionais que incluem uma mesma dieta da eclosão até as três semanas de idade, tendo os valores nutricionais dos alimentos utilizados para esta fase sido determinados com galos adultos ou frangos de corte na fase de crescimento.

1. Mestre em Zootecnia, com concentração em Nutrição de Monogástricos pela Universidade Federal de Lavras/UFLA - Caixa Postal 3037 - $37.200-000$ Lavras, MG.

2. Professor Titular do Departamento de Zootecnia/ UFLA.

3. Professor adjunto do Departamento de Zootecnia da UNIFENAS.

4. Doutorando em Zootecnia/ UFLA.

5. Mestrando em Zootecnia/ UFLA. 
Assim, existe uma grande preocupação sobre a aplicabilidade desses valores para pintos na fase préinicial, notando-se um crescente interesse por uma dieta própria. Por outro lado, existem poucas informações sobre as exigências nutricionais e, principalmente, sobre o valor energético dos alimentos durante esta fase.

Assim, o objetivo deste estudo foi determinar os valores energéticos de diferentes fontes protéicas para pintos de corte na fase pré-inicial.

A energia não é propriamente um nutriente, mas sim uma propriedade na qual os nutrientes produzem energia, quando oxidados pelo metabolismo (NRC, 1994).

Como descreve o NRC (1994), a energia metabolizável aparente (EMA) é a diferença entre a energia bruta consumida na ração e a energia bruta excretada. Sibbald (1976) descreve energia metabolizável verdadeira (EMV) como uma modificação na metodologia empregada para verificar a EMA dos alimentos, na qual considera as perdas endógenas (fecal metabólica e urinária endógena), sendo os valores obtidos com aves mantidas em jejum.

Vários fatores afetam os valores de EM, entre os quais a idade das aves, o alimento, composição química, níveis de cálcio e fósforo, nível de inclusão do ingrediente teste, taxa de consumo, metodologia utilizada para determinação da EM e os fatores antinutricionais dos alimentos. Assim, na tentativa de redução dessas variações o balanço de nitrogênio (BN) é utilizado, podendo ser negativo ou positivo. Hill e Anderson (1958) propuseram um valor de correção para o nitrogênio retido de $8,22 \mathrm{kcal} / \mathrm{g}$ de nitrogênio, já que essa é a energia que fica retida quando o ácido úrico é completamente oxidado, para se determinar a energia metabolizável aparente e verdadeira corrigidas para balanço de nitrogênio (EMAn, EMVn).

\section{MATERIAL E MÉTODOS}

Foi conduzido um experimento nas instalações experimentais do Setor de Avicultura do Departamento de Zootecnia da Universidade Federal de Lavras (UFLA). O experimento foi realizado num período de 7 dias, durante o mês de maio de 2003, utilizando-se um galpão de alvenaria, com ambiente controlado. A temperatura média registrada durante o período experimental foi de $29^{\circ} \mathrm{C}$, na qual a mínima registrada foi de $27^{\circ} \mathrm{C}$ e a máxima de $31^{\circ} \mathrm{C}$. A umidade média foi de $60 \%$. Foram utilizadas gaiolas de metabolismo providas de bandejas coletoras de excretas revestidas com plástico. Os bebedouros usados foram do tipo pressão e comedouro individual, de calha com borda para evitar desperdício.

Nove tratamentos foram utilizados durante a fase pré-inicial, sendo uma ração referência e oito rações combinadas com alimento teste, segundo a metodologia de substituição de Matterson et al. (1965). Todos os alimentos testados se enquadravam no grupo dos alimentos protéicos. Cada alimento teste constou de 6 repetições distribuídas aleatoriamente, sendo a unidade experimental composta por 8 aves. Ao total, foram utilizados 480 pintos machos da linhagem Cobb, provenientes de incubatório comercial, com 1 dia de idade.

Foram avaliados 4 alimentos protéicos de origem vegetal (farelo de soja, soja integral tostada, soja micronizada e farelo e glúten de milho), que substituíram a ração referência em $30 \%$ e 4 alimentos protéicos de origem animal (farinhas de carne e ossos $40 \%$ e $45 \%$ de $\mathrm{PB}$, farinha de peixe e farinha de vísceras), que substituíram a ração referência em $20 \%$.

Os pintos foram distribuídos nas gaiolas no momento da chegada do incubatório, onde receberam ração e água à vontade, por seis dias, sendo dois dias para adaptação e quatro dias para coleta total.

O consumo de ração durante o período de coleta foi registrado e as coletas foram realizadas duas vezes ao dia, às 8 horas e às 16 horas, para evitar possível fermentação das excretas. As excretas coletadas foram acondicionadas em sacos plásticos previamente identificados e armazenadas em freezer até o período final de coleta. Então, as excretas foram descongeladas, pesadas, homogeneizadas e delas retiradas alíquotas para análises, as quais sofreram uma pré-secagem em estufa ventilada a $55^{\circ} \mathrm{C}$, por 72 horas. A seguir, as amostras foram moídas em moinho tipo faca, com peneira de $2 \mathrm{~mm}$ e analisadas quanto à matéria seca (MS), energia bruta (EB) e nitrogênio (N), segundo a metodologia de Silva (1990).

Simultaneamente, foram mantidas 48 aves em jejum, distribuídas em 6 repetições de 8 aves, que passaram por 48 horas de adaptação com a ração referência. A partir daí, entraram em jejum por um período de 4 horas, para promover a limpeza do trato digestório e por mais 48 horas para determinar as perdas endógenas e metabólicas, equivalentes ao quarto e quinto dias de vida da ave. Os valores das perdas endógenas e metabólicas foram corrigidos para os 4 dias de coleta, para se determinar a energia metabolizável verdadeira (EMV) e energia metabolizável verdadeira corrigida (EMVn).

As variáveis calculadas foram energia metabolizável aparente (EMA), aparente corrigida para 
balanço de nitrogênio (EMAn), verdadeira (EMV) e verdadeira corrigida para balanço de nitrogênio (EMVn), baseadas nas fórmulas propostas por Matterson et al. (1965). Para determinar a precisão das estimativas foi utilizado o desvio-padrão das médias dos tratamentos. Para cada alimento foram determinadas a matéria seca (MS), proteína bruta (PB), extrato etéreo (EE), energia bruta (EB), conforme as técnicas descritas por Silva (1990). Todas as análises foram realizadas no Laboratório de Nutrição Animal do Departamento de Zootecnia da UFLA. A ração referência foi formulada a partir das recomendações de Rostagno et al. (2000) para frangos de corte na fase pré-inicial (Tabela 1).

As fórmulas utilizadas no cálculo dos valores energéticos foram:

TABELA 1 - Composição centesimal da ração referência e valores nutricionais utilizados para pintos de corte na fase pré-inicial (1 a 7 dias de idade).

\begin{tabular}{|c|c|}
\hline INGREDIENTE & kg \\
\hline Milho & 57,386 \\
\hline Farelo de soja & 36,676 \\
\hline Fosfato bicálcico & 1,894 \\
\hline Calcário calcítico & 0,999 \\
\hline DL-metionina (99\%) & 0,250 \\
\hline L-lisina (99\%) & 0,185 \\
\hline Óleo de soja & 1,877 \\
\hline Sal comum & 0,458 \\
\hline Suplemento vitamínico ${ }^{1}$ & 0,100 \\
\hline Suplemento mineral $^{2}$ & 0,100 \\
\hline Anticcocidiano $^{3}$ & 0,050 \\
\hline Promotor $^{4}$ & 0,025 \\
\hline TOTAL & 100,000 \\
\hline \multicolumn{2}{|l|}{ VALORES CALCULADOS } \\
\hline Proteína bruta (\%) & 21,915 \\
\hline Energia metabolizável (kcal/kg) & 2.950 \\
\hline Metionina (\%) & 0,507 \\
\hline Metionina + cistina (\%) & 0,926 \\
\hline Lisina (\%) & 1,307 \\
\hline Cálcio (\%) & 0,988 \\
\hline Fósforo disponível (\%) & 0,466 \\
\hline Sódio (\%) & 0,224 \\
\hline \multicolumn{2}{|c|}{ 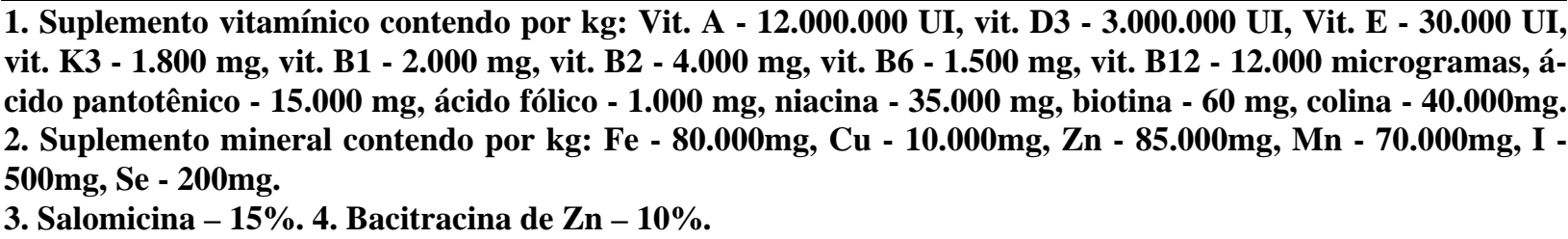 } \\
\hline
\end{tabular}

Ciênc. agrotec., Lavras, v. 29, n. 1, p. 238-244, jan./fev. 2005 
EMA da $(\mathrm{RT})$ ou $(\mathrm{RR})(\mathrm{kcal} / \mathrm{kg}$ MS) $=\underline{\text { EBingerida }- \text { EBexcretada }}$ MS ingerida

EMA do alimento $(\mathrm{kcal} / \mathrm{kg} \mathrm{MS})=\mathrm{EMA}_{\mathrm{RR}}+($ EMART - EMARR $)$ g/g de substituição

EMAn da RT ou RR $(\mathrm{kcal} / \mathrm{kg}$ MS $)=$ EB ingerida $-($ EBexcretada $+8,22 *$ BN $)$ MS ingerida

EMAn do alimento $(\mathrm{kcal} / \mathrm{kg}$ MS $)=$ EMA $_{\mathrm{RR}}+($ EMART- EMARR $)$ g/g de substituição

em que:

$\mathrm{BN}=$ Balanço de nitrogênio $=\mathrm{N}$ ingerido $-\mathrm{N}$ excretado

$\mathrm{RT}=$ Ração teste e $\mathrm{RR}=$ Ração referência.

EMV da RT e RR (kcal/kg MS $)=$ EB ingerida $-($ EBexcretada - EBendógena $)$ MS ingerida

EMV do alimento $(\mathrm{kcal} / \mathrm{kg}$ de MS $)=\mathrm{EMV}_{\mathrm{RR}}+(\underline{\text { EMVRT }- \text { EMVRR }})$ g/g de substituição

EMVndaRTeRR(kcalkg MS)=EBingenida-(EBexaetada-EBendógena+8,22*BNV) MS ingerida

EMVn do alimento (kcal/kg MS) $=\mathrm{EMVn}_{\mathrm{RR}}+($ EMVnRT - EMVnRR $)$ g/g de substituição

em que:

$\mathrm{BNV}=\mathrm{BN}$ verdadeiro $=[\mathrm{N}$ ingerido $-(\mathrm{N}$ excretado $-\mathrm{N}$ endógeno $)$

\section{RESULTADOS E DISCUSSÃO}

Os valores de energia metabolizável aparente e aparente corrigida para balanço de nitrogênio, expressos na base de matéria seca estão apresentados na Tabela 2 .

Os valores energéticos, na base de matéria seca, determinados com pintos de corte de 1 a 7 dias de idade, mostraram-se diferentes dos encontrados na literatura nacional (EMBRAPA, 1991; ROSTAGNO et al., 2000) e internacional (NRC, 1994; REFERENCE..., 2001). A composição química, digestibilidade e os métodos de processamento dos alimentos, assim como a idade das aves submetidas ao ensaio, nível de inclusão do alimento, taxa de consumo de alimentos e as diferentes metodologias empregadas, podem ser uma causa provável destas variações.

É importante ressaltar que os valores energéticos encontrados na tabela de Rostagno et al. (2000) foram determinados com aves de diferentes idades (pintos, galos e galinhas poedeiras), o que pode gerar valores diferentes dos encontrados no presente trabalho. Nas outras tabelas referenciadas, os valores energéticos foram determinados com aves de 1 a 21 dias de idade, o que torna possível uma variação nestes valores.

Os valores médios de EMA das fontes vegetais estudadas foram 8,6\% superiores aos valores encontrados para a EMAn, assim como para as fontes de origem animal, que foram 14,8\% superiores. De acordo com Wolynetz e Sibbald (1984), em condições de consumo à vontade, a EMA é maior que a EMAn, quando a retenção de nitrogênio é positiva. Como neste estudo as aves apresentaram consumo ad libitum, sendo o nitrogênio retido maior que zero, conseqüentemente, a EMA superou os valores de EMAn.

Os valores de EMAn dos alimentos encontrados no presente trabalho, em relação aos valores descritos por Rostagno et al. (2000), encontram-se na Tabela 3.

Comparando-se os valores da EMAn dos alimentos protéicos de origem vegetal estudados neste trabalho com os valores de tabelas nacionais (EMBRAPA, 1991; ROSTAGNO et al., 2000) e de tabelas internacionais (NRC, 1994; REFERENCE..., 2001), observou-se que estes foram de $6 \%$ a $17 \%$ inferiores. Esse resultado pode ser atribuído à diferença na idade das aves utilizadas em ambos os ensaios, uma vez que os pintos, na primeira semana de vida, ainda não estão completamente desenvolvidos fisiologicamente. Dessa forma, os alimentos tendem a apresentar uma melhor digestibilidade com o avançar da idade, o que influencia na superioridade dos valores energéticos. Este fato pode estar relacionado a uma menor taxa de passagem, que permite maior tempo de permanência dos nutrientes no TGI sob ação enzimática nas aves adultas (BURNELL et al., 1990).

Dentre os alimentos de origem animal utilizados, a farinha de carne e ossos (FCO) apresentou valor de EMAn superior ao das tabelas de EMBRAPA (1991), NRC (1994), Rostagno et al. (2000) e Reference... (2001), variando de $5 \%$ à $26 \%$. A baixa digestibilidade desta farinha e as diferenças na composição podem explicar este resultado, uma vez que este é um subproduto de origem animal que pode apresentar grande variação na sua composição em nutrientes em função da sua composição química e condições no processamento. Outro motivo seria a diferença na idade das aves utilizadas para ambos os ensaios. Entretanto, as outras farinhas mostraram-se superiores energeticamente, quando comparadas com as mesmas tabelas.

O valor encontrado de EMAn para FCO 40\% de PB foi $4 \%$ superior ao valor obtido por EMBRAPA (1991) e 26\% superior àquele relatado por Rostagno et al. (2000). Isso ocorreu devido ás variações na composição química, expressas principalmente pelos teores de $\mathrm{EE}, \mathrm{EB}$ e PB, que se mostraram superiores em relação às tabelas citadas. A farinha de vísceras apresentou valores de EMAn até 6\% superiores aos destas tabelas e o valor da EMAn da farinha de peixe (3.492 kcal/kg) foi superior àqueles relatados por EMBRAPA (1991), NRC (1994), Rostagno et al. (2000) e Reference... (2001), e 
os quais apresentaram valores de 3.099, 2.955, 2.804 e $2.605 \mathrm{kcal}$ de EMAn/kg de MS, respectivamente.

Dentro do grupo dos alimentos protéicos de origem animal, comparando-se os valores de EMAn das farinhas de carne e ossos em relação à farinha de peixe, verificouse que estes foram inferiores. Uma justificativa provável seria as diferenças no perfil de ácidos graxos que compõem estes ingredientes. A farinha de carne e ossos possui uma maior quantidade de ácidos graxos saturados, enquanto que a farinha de peixe possui ácidos graxos insaturados. Este fato influencia o aproveitamento destes alimentos, uma vez que os pintinhos apresentam maior capacidade de absorção dos ácidos graxos insaturados.

Os valores de energia metabolizável verdadeira e verdadeira corrigida para balanço de nitrogênio dos alimentos estão apresentados na Tabela 4.

Os resultados dos valores de EMV e EMVn obtidos neste trabalho apresentaram-se variáveis em relação aos da literatura (NRC, 1994; EMBRAPA, 1991;
ROSTAGNO et al., 2000; REFERENCE..., 2001), devido à diferenças na idade e na composição química e digestibilidade dos alimentos utilizados. Os valores médios de EMV das fontes vegetais e animais estudadas foram de $9 \%$ a $15 \%$ superiores aos valores encontrados para EMVn, sendo essa variação semelhante à encontrada para EMA e EMAn.

Os alimentos protéicos de origem animal apresentaram valores de EMVn superiores aos encontrados nas tabelas referenciadas, com exceção da FCO $45 \%$ de PB, que se apresentou inferior aos valores tabelados, enquanto que os alimentos de origem vegetal apresentaram valores inferiores. Essas variações nos valores sugerem que os pintos na primeira semana de idade têm uma capacidade diferenciada de aproveitamento dos nutrientes, de acordo com o alimento e suas características.

TABELA 2 - Energia metabolizável aparente e aparente corrigida para balanço de nitrogênio dos alimentos, determinada com pintos de 1 a 7 dias de idade e seus respectivos desvios padrões (valores expressos na matéria seca).

\begin{tabular}{lcc}
\hline \multicolumn{1}{c}{ Alimentos } & $\begin{array}{c}\text { EMA }^{\mathbf{1}} \\
\mathbf{( k c a l / k g )}\end{array}$ & $\begin{array}{c}\text { EMAn }^{2} \\
\mathbf{( k c a l / k g )}\end{array}$ \\
\hline Farelo de soja & $2643 \pm 224^{3}$ & $2365 \pm 183$ \\
Soja integral tostada & $3662 \pm 130$ & $3427 \pm 128$ \\
Soja micronizada & $4322 \pm 278$ & $4022 \pm 260$ \\
Farelo de glúten de milho & $4113 \pm 153$ & $3762 \pm 214$ \\
\hline Média & $3685 \pm 688$ & $3394 \pm 671$ \\
\hline Farinha de carne e ossos 40\% de PB & $3131 \pm 288$ & $2849 \pm 270$ \\
Farinha de carne e ossos 45\% de PB & $2431 \pm 161$ & $2065 \pm 179$ \\
Farinha de peixe & $4092 \pm 225$ & $3492 \pm 201$ \\
Farinha de vísceras & $3848 \pm 284$ & $3360 \pm 237$ \\
\hline Média & $3375 \pm 702$ & $2941 \pm 609$ \\
\hline
\end{tabular}

${ }^{1}$ Energia metabolizável aparente

${ }^{2}$ Energia metabolizável aparente corrigida para balanço de nitrogênio

${ }^{3}$ Desvio padrão da média

Ciênc. agrotec., Lavras, v. 29, n. 1, p. 238-244, jan./fev. 2005 
TABELA 3 - Energia metabolizável aparente corrigida para balanço de nitrogênio (EMAn) dos alimentos, em relação a Rostagno et al. (2000), valores expressos na matéria seca.

\begin{tabular}{lccc}
\hline \multicolumn{1}{c}{ Alimentos } & $\begin{array}{c}\text { EMAn } \\
\mathbf{( k c a l / k g )}\end{array}$ & $\begin{array}{c}\text { EMAn Rostagno } \\
\mathbf{( k c a l / k g )}\end{array}$ & $\begin{array}{c}\text { Diferença } \\
\mathbf{( \% )}\end{array}$ \\
\hline Farelo de soja & 2365 & 2875 & 17 \\
Soja integral tostada & 3427 & 3651 & 6 \\
Soja micronizada & 4022 & 4273 & 6 \\
Farelo de glúten de milho & 3762 & 4161 & 10 \\
Farinha de carne e ossos 40\% de PB & 2849 & 2103 & 26 \\
Farinha de carne e ossos 45\% de PB & 2065 & 2173 & 5 \\
Farinha de peixe & 3492 & 2955 & 15 \\
Farinha de vísceras & 3360 & 3224 & 4 \\
\hline
\end{tabular}

TABELA 4 - Energia metabolizável verdadeira e verdadeira corrigida dos alimentos, determinada com pintos de 1 a 7 dias de idade e seus respectivos desvios-padrões (valores expressos na matéria seca).

\begin{tabular}{lcc}
\hline \multicolumn{1}{c}{ Alimentos } & $\begin{array}{c}\mathbf{E M V}^{\mathbf{1}} \\
\mathbf{( k c a l / k g )}\end{array}$ & $\begin{array}{c}\mathbf{E M V n}^{\mathbf{2}} \\
\mathbf{( k c a l / k g )}\end{array}$ \\
\hline Farelo de soja & $2687 \pm 218^{3}$ & $2394 \pm 179$ \\
Soja integral tostada & $3717 \pm 131$ & $3465 \pm 129$ \\
Soja micronizada & $4385 \pm 274$ & $4065 \pm 257$ \\
Farelo de glúten de millho & $4200 \pm 151$ & $3821 \pm 215$ \\
Média & $3747 \pm 699$ & $3437 \pm 678$ \\
Farinha de carne e ossos 40 & $3207 \pm 287$ & $2901 \pm 270$ \\
Farinha de carne e ossos 45 & $2526 \pm 153$ & $2129 \pm 167$ \\
Farinha de peixe & $4146 \pm 258$ & $3530 \pm 222$ \\
Farinha de vísceras & $3888 \pm 270$ & $3388 \pm 227$ \\
Média & $3442 \pm 684$ & $2987 \pm 597$ \\
\hline
\end{tabular}

${ }^{1}$ Energia metabolizável verdadeira

${ }^{2}$ Energia metabolizável verdadeira corrigida para balanço de nitrogênio

${ }^{3}$ Desvio padrão da média

Ciênc. agrotec., Lavras, v. 29, n. 1, p. 238-244, jan./fev. 2005 


\section{CONCLUSÕES}

Os valores de EMAn encontrados para o farelo de soja, soja integral tostada, soja micronizada e farelo de glúten de milho foram, respectivamente, de 2.365, 3.427, 4.022 e $3.762 \mathrm{kcal} / \mathrm{kg}$ de MS. Já os valores encontrados para a farinha de carne e ossos $40 \%$ PB, FCO $45 \%$ PB, farinha de peixe e farinha de vísceras foram, respectivamente, $2.849,2.065,3.492$ e $3.360 \mathrm{kcal} / \mathrm{kg}$ de MS.

O farelo de soja, soja integral tostada, soja micronizada e farelo de glúten de milho obtiveram valores de EMVn de 2.394, 3.465, 4.065 e 3.821 kcal/kg de MS, respectivamente. Já os valores encontrados para a farinha de carne e ossos $40 \% \mathrm{~PB}$, FCO $45 \% \mathrm{~PB}$, farinha de peixe e farinha de vísceras foram, respectivamente, de 2.901, 2.129, 3.530 e $3.388 \mathrm{kcal} / \mathrm{kg}$ de MS.

As correções do balanço de nitrogênio reduzem os valores energéticos, em média, de $9 \%$ a $15 \%$ para as fontes protéicas vegetais e animais estudados, respectivamente.

\section{REFERÊNCIAS BIBLIOGRÁFICAS}

BURNELL, T. W.; CROMWELL, G. L.; STAHLY, T. S. Effects of particle size on the biological availability of calcium and phosohorus in defluorinated phosphate for chicks. Poultry Science, Champaign, v. 69, p. 11101117, 1990.

EMPRESA BRASILEIRA DE PESQUISA AGROPECUÁRIA. Tabela de composição química e valores energéticos de alimentos para suínos e aves. Concórdia, SC: EMBRAPA/CNPSA, 1991. 97 p.
HILL, F. W.; ANDERSON, D. L. Comparison of metabolizable energy and produtive energy determinations whit growing chicks. Journal Nutrition, Davis, v. 64, n. 3, p. 587-604, 1958.

MATTERSON, L. D. et al. The metabolizable energy of feeds ingredients for chickens. Connecticut: The university of Connecticut, 1965. 11 p. (Research report, 7).

NATIONAL RESEARCH COUNCIL. Nutrient requeriments of poultry. 9. ed. New York, 1994. $155 \mathrm{p}$.

REFERENCE issue e buyers guide. Feedstuffs, Minneapolis, v. 73, n. 29, p. 220, 2001.

ROSTAGNO, H. S. et al. Composição de alimentos e exigências nutricionais de aves e suínos: tabelas brasileiras. Viçosa: UFV, 2000. 141 p.

SIBBALD, I. R. A biossay for metabolizable energy in feedingstuffs. Poultry Science, Champing, v. 55, n. 1, p. 303-308, 1976.

SILVA, D. J. Análise de alimentos: métodos químicos e biológicos. 2. ed. Viçosa: UFV, 1990. 165 p.

WOLYNETZ, M. N.; SIBBALD, I. R. Relationships between apparent na true metabolizable energy and the effects of a nitrogen correction. Poultry Science, Champing, v. 63, n. 7, p. 1386-1399, 1984. 
